\title{
The subjective acceptance in presbyopic patient receiving correction based on conventional method of age $\mathrm{v} / \mathrm{s}$ amplitude of accommodation
}

\author{
Chaudhary NP ${ }^{1}$, Gautam PS $^{2}$
}

\begin{abstract}
Objective: To observe the subjective acceptance in presbyopic patients following prescription of spectacles. Material and method: This is a hospital based cross sectional study which was conducted in 100 presbyopic patients in age group of 35 to 60 years at outpatient department of ophthalmology in Nobel Medical College Teaching Hospital, kanchanbari from $1^{\text {st }}$ August 2018 to $30^{\text {th }}$ November 2018. The patients were divided into two groups, First group received the presbyopic correction according to conventional method of age and the second group received the prescription according to their amplitude of accommodation. Patient's satisfaction in terms of symptoms like eyestrain, headache or difficulty with the usage of glasses was noted. The data collected were subjected to statistical analysis. Conclusion: When presbyopic correction is given according to amplitude of accommodation in patients belonging to 36-45 years age group, it is tolerated better and patients are more satisfied in terms of symptoms like eyestrain and headache than getting the simple correction as per their age. However after the age of 45 years, presbyopic correction given according to age is equally tolerated well among all refractive error groups. Results: 100 patients in this study who visited our OPD with presbyopic symptoms were divided into two groups, each of 50 patients. Patient's satisfaction and tolerance was better when presbyopic correction was given on the basis of their amplitude of accommodation in age group 36-45, in comparison to the prescription given according to conventional method of their age. However, there was no statistically significant difference in the patient's satisfaction level in the two groups after the age of 45.
\end{abstract}

Key words: Amplitude of accommodation, presbyopia, refractive error

\section{INTRODUCTION}

Presbyopia is defined as the reduction in the range of accommodation or accommodative power which occurs with ageing. Uncorrected presbyopia results in an inability to perform which result in receding of Normal Near point effortless near tasks at a customary working distance with attendant visual symptoms. Presbyopia poses an important public health challenge because its onset coincides with the productive year of an individual which may affect productivity and subsequently hinder economic development of a nation. The definition of presbyopia is fluid because there is no standard distance for near work ${ }^{1}$. The age at which patients seek remedy for presbyopic symptoms vary and it is not unusal to see patients in their late forties, not using presbyopic lenses. This variability could be either professional or due to variable preservation of accommodative ability or artifactual due to Myopia. Symptoms of presbyopia itself can be dependent on other factors like amount of near work done, lighting conditions, and corrected distance acuity etc ${ }^{2}$.

The pathophysiology of presbyopia still remains poorly

1. Neha Priyadarshani Chaudhary

2. Pramod Sharma Gautam

Address for correspondence:

Dr. Neha Priyadarshani Chaudhary

Department of Ophthalmology

Nobel Medical College

Biratnagar, Morang, Nepal

Email: chy.neha22@gmail.com understood. According to a theory proposed by Helmholtz, accommodation occurs as a result of the elastic properties of the lens and possibly the vitreous that allows the lens to expand and increase its power when zonular tension is relieved during ciliary muscle contraction ${ }^{3}$. As the lens changes with age, the ability to expand and increase refractive power is lost. Helmholtz's theory of sclerosis of the crystalline lens as the cause of presbyopia has been challenged in 1992 by Schachar ${ }^{4}$. Schachar suggests that the longitudinal muscle fibers of the ciliary muscle contract during accommodation, placing more tension on the equatorial zonules, while relaxing the anterior and posterior zonules ${ }^{4}$. This force distribution causes an increase in the equatorial diameter of the lens, decreasing the peripheral volume while increasing the central volume. As the central volume increases, so does the power of the lens. Under this theory, presbyopia occurs because of the increasing equatorial diameter of the aging lens. Once the lens diameter reaches a critical size, usually during the fifth decade of life, the resting tension on the zonules is significantly reduced ${ }^{5}$.

\section{CORRECTION OF PRESBYOPIA}

The treatment of presbyopia is to provide the patient with convex lenses so that his accommodation is reinforced and his near point brought within the useful working distance. To do this adequately we must first know the working point of the individual. An individual is to be treated as an individual and his needs are his own needs and the individual is not to be given correction for presbyopia merely because he is in the presbyopic age. Rather the person's refractive status and the amplitude of accommodation should be taken into account whenever prescribing presbyopic correction ${ }^{6}$. 
According to the Donder's rule, $1 \backslash 4$ of amplitude of accommodation should be kept in reserve for comfortable near work and it should be kept in mind that majority of people work at a distance of $28-30 \mathrm{~cm}$ and for maximum comfort in near work, at least $1 / 3$ of the available accommodative power must be kept in reserve ${ }^{7}$.

To the best of my knowledge, I found study showing the patient's level of satisfaction and comfort after receiving presbyopic correction with spectacles. Also, there is little data on the actual differences in accommodation that is preserved in various types of refractive errors. Hence, this study is aimed to compare the subjective acceptance in patients receiving presbyopic correction with glasses according to conventional age method over the correction according to their amplitude of accommodation.

\section{MATERIAL AND METHODS}

This was a hospital based cross - sectional study on the patients with presbyopic symptoms who visited the outpatient department of ophthalmology in Nobel Medical College and teaching Hospital from 1st August 2018 to 30th Novemebr 2018, provided they fulfilled the inclusion and exclusion criteria mentioned below.

\section{INCLUSION CRITERIA}

- Patients between 35-60 yrs of age

- Clear ocular media

- Visual acuity improving to $6 / 6$ on snellen's refraction

\section{EXCLUSION CRITERIA}

- Age $<35$ yrs of age and $>60$ yrs.

- Hazy ocular media including corneal opacity and cataract> grade NO1, NC1,C1, P1 according to LOCS III cataract classification ${ }^{[9]}$

- Spherical correction of more than $6.0 \mathrm{D}$

- Cylindrical correction of more than $0.75 \mathrm{D}$ cylindrical

- Patients of strabismus or with history of diabetes mellitus, systemic illness, trauma, drug therapy.

A total of 100 cases were included in the study. All the cases were examined for refractive status and their amplitude of accommodation was measured with the help of RAF ruler and the patients were divided into 2 groups, 50 in each: one group was prescribed presbyopic correction according to age and the second group, according to amplitude of accommodation. When prescribing according to age, the conventional method of prescribing $+1 \mathrm{D}$ at the age of $40 \mathrm{yrs}$ and thereafter adding $+0.5 \mathrm{D}$ for every 5 years was followed. On the other hand in patients who are prescribed presbyopic correction according to amplitude of accommodation, $1 / 3^{\text {rd }}$ of Amplitude of Accommodation was kept in reserve, for comfortable sustained vision. For example, if a patient who had his near point at 50 $\mathrm{cms}$, his amplitude of accommodation would be 2D, but for or a normal working distance of $25 \mathrm{cms}$, he required an amplitude of accommodation of 4D, and to work comfortably he must keep $1 \backslash 3$ of his accommodation in reserve i.e. $1 \backslash 3$ of $2 \mathrm{D}$ or 0.7 $D$, so the corrective presbyopic lens he was given was that of 2.7D (4-2+0.7).

Patient's satisfaction in terms of symptoms like eyestrain, headache or difficulty with the usage of glasses was noted. Patients with any of these symptoms were considered as not satisfied. A follow up examination was done at 2 weeks after prescription of presbyopic correction and acceptance of correction.

\section{Analysis and Statistics}

The data collected was tabulated and results of study were analyzed using statistical package for social science (SPSS) 16.0 and Microsoft Word and Microsoft Excel have been used to generate graphs, tables, etc. Significance level was assessed by calculating ' $p$ ' value using student $T$ test. Observations were taken as significant at ' $p$ ' value less than $0.05(' p$ ' $<0.05)$.

\section{RESULTS}

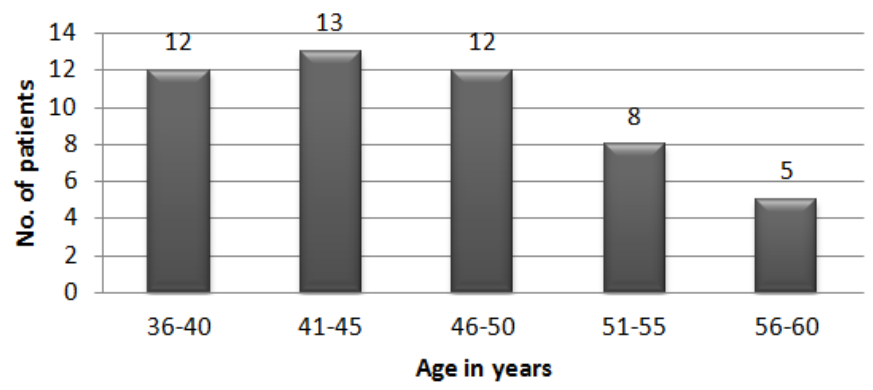

Figure I: Age distribution on group I

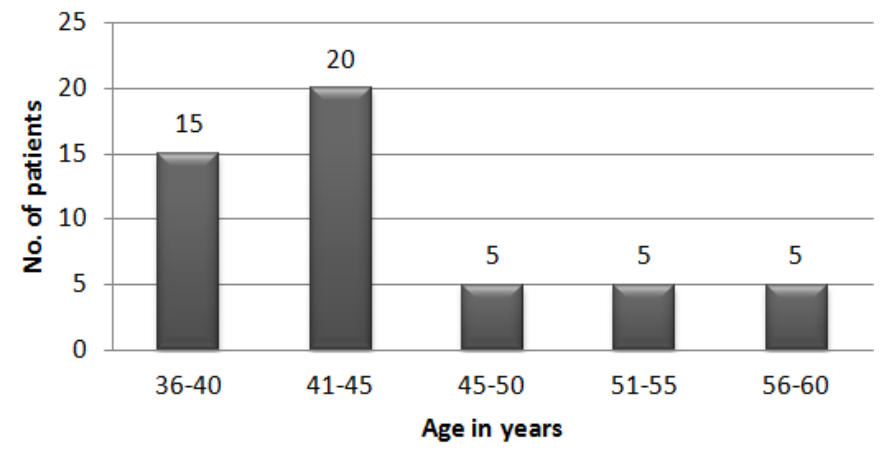

Figure II: Age distribution on group II 


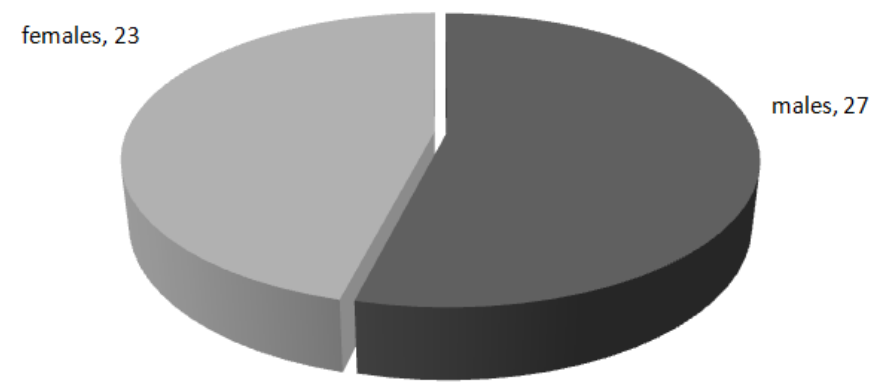

Figure 3: Sex distribution in Group I

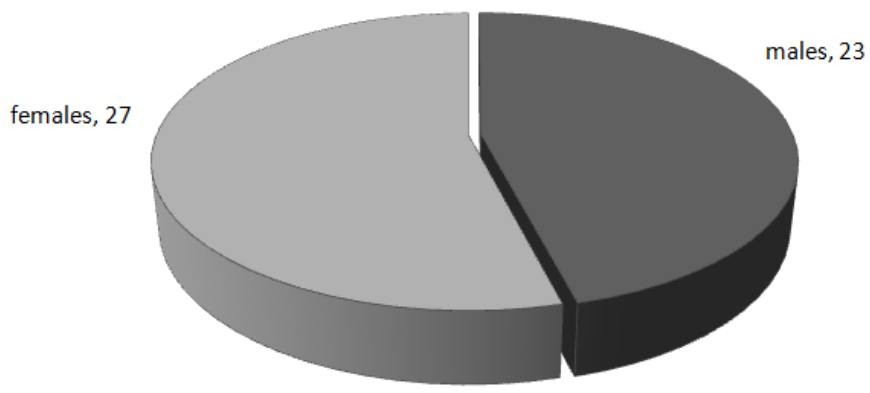

Figure 4: Sex distribution in Group I

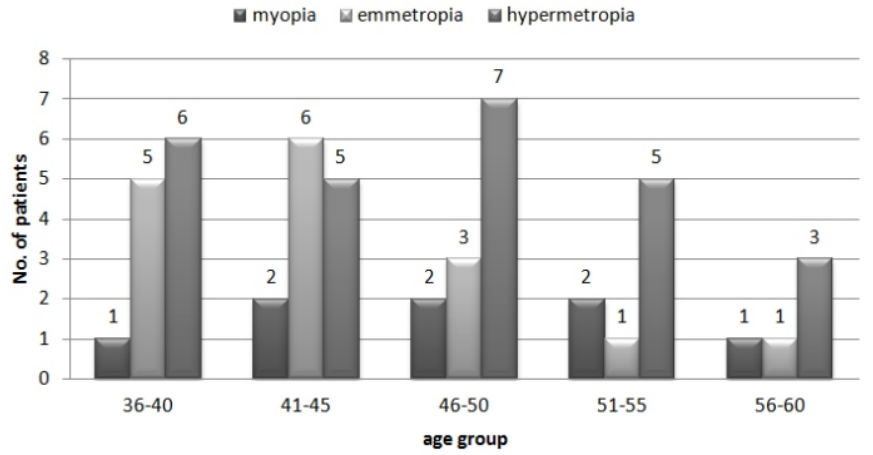

Figure 5: Refractive status of pts in gr-I

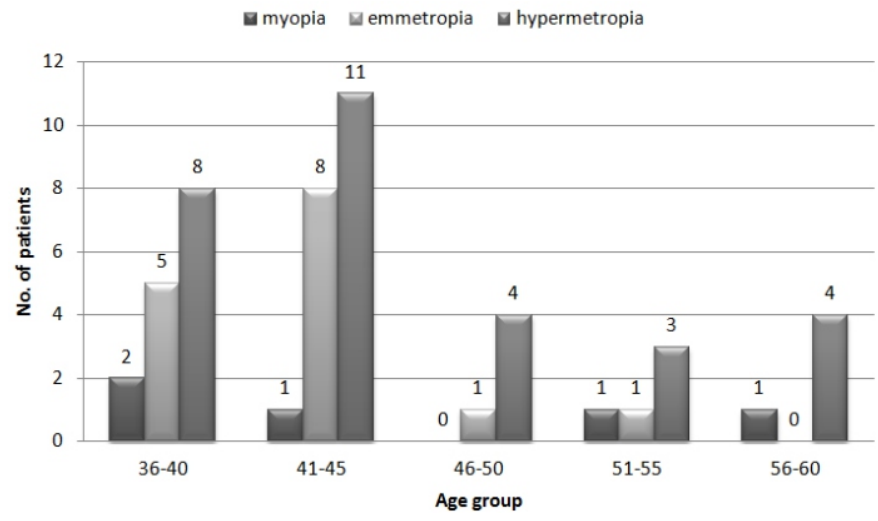

Figure 6: Refractive status of pts in gr-II

\begin{tabular}{|c|c|c|c|c|c|c|c|c|c|c|c|c|}
\hline \multirow{3}{*}{$\begin{array}{l}\text { Age } \\
\text { Group } \\
\text { (years) }\end{array}$} & \multicolumn{4}{|c|}{ Myopia } & \multicolumn{4}{|c|}{ Hypermetropia } & \multicolumn{4}{|c|}{ Emmetropia } \\
\hline & \multirow[t]{2}{*}{$\begin{array}{l}\text { No of } \\
\text { cases }\end{array}$} & \multicolumn{3}{|c|}{$\begin{array}{c}\% \\
\text { Satisfaction }\end{array}$} & \multirow[t]{2}{*}{$\begin{array}{l}\text { No of } \\
\text { cases }\end{array}$} & \multicolumn{3}{|c|}{$\begin{array}{c}\% \\
\text { Satisfaction }\end{array}$} & \multirow[t]{2}{*}{$\begin{array}{l}\text { No of } \\
\text { cases }\end{array}$} & \multicolumn{3}{|c|}{$\begin{array}{c}\% \\
\text { Satisfaction }\end{array}$} \\
\hline & & Yes & no & $\%$ & & Yes & no & $\%$ & & Yes & no & $\%$ \\
\hline $36-40$ & 01 & 00 & 01 & 00 & 06 & 00 & 06 & 00 & 05 & 00 & 05 & 00 \\
\hline $41-45$ & 02 & 01 & 01 & 50 & 05 & 01 & 04 & 20 & 06 & 03 & 03 & 50 \\
\hline $46-50$ & 02 & 01 & 01 & 50 & 07 & 04 & 03 & 57.2 & 03 & 03 & 00 & 100 \\
\hline $51-55$ & 02 & 02 & 00 & 100 & 05 & 05 & 00 & 100 & 01 & 01 & 00 & 100 \\
\hline $56-60$ & 01 & 00 & 01 & 00 & 03 & 03 & 00 & 100 & 01 & 01 & 00 & 100 \\
\hline
\end{tabular}

Table I: Patient satisfaction after presbyopic correction according to age (group I)

\begin{tabular}{|c|c|c|c|c|c|c|c|c|c|c|c|c|}
\hline \multirow{3}{*}{$\begin{array}{l}\text { Age } \\
\text { Group } \\
\text { (years) }\end{array}$} & \multicolumn{4}{|c|}{ Myopia } & \multicolumn{4}{|c|}{ Hypermetropia } & \multicolumn{4}{|c|}{ Emmetropia } \\
\hline & \multirow[t]{2}{*}{$\begin{array}{l}\text { No of } \\
\text { cases }\end{array}$} & \multicolumn{3}{|c|}{$\begin{array}{c}\% \\
\text { Satisfaction }\end{array}$} & \multirow[t]{2}{*}{$\begin{array}{l}\text { No of } \\
\text { cases }\end{array}$} & \multicolumn{3}{|c|}{$\begin{array}{c}\% \\
\text { Satisfaction }\end{array}$} & \multirow[t]{2}{*}{$\begin{array}{l}\text { No of } \\
\text { cases }\end{array}$} & \multicolumn{3}{|c|}{$\begin{array}{c}\% \\
\text { Satisfaction }\end{array}$} \\
\hline & & Yes & no & $\%$ & & Yes & no & $\%$ & & Yes & no & $\%$ \\
\hline $36-40$ & 02 & 02 & 00 & 100 & 08 & 08 & 00 & 100 & 05 & 03 & 02 & 60 \\
\hline $41-45$ & 01 & 01 & 00 & 100 & 11 & 10 & 01 & 90.9 & 08 & 07 & 01 & 87.5 \\
\hline $46-50$ & 00 & 00 & 00 & 00 & 04 & 04 & 00 & 100 & 01 & 01 & 00 & 100 \\
\hline $51-55$ & 01 & 01 & 00 & 100 & 03 & 03 & 00 & 100 & 01 & 01 & 00 & 100 \\
\hline $56-60$ & 01 & 00 & 01 & 0 & 04 & 04 & 00 & 100 & 00 & 00 & 00 & 00 \\
\hline
\end{tabular}

Table II: Patient satisfaction after presbyopic correction according to amplitude of accommodation 
Table I shows patients satisfaction after presbyopic correction according to age. There was $0 \%$ satisfaction in all 3 refractive error groups in age group 36-40 years, 50\% satisfaction in myopic patients in age groups $41-45$ and $46-50$ and $100 \%$ satisfaction in all 3 refractive error groups in age groups $51-55$ years.

Table II shows patients satisfaction after presbyopic correction according to amplitude of accommodation in group II. It showed $100 \%$ satisfaction in myopes and hypermetropes in age group $36-40$ and $51-55$ years, $60 \%$ satisfaction in emmetropes in $36-40$ years age group; $90.9 \%$ and $87.5 \%$ satisfaction of hypermetropes and emmetropes in the age group $41-45$ years respectively.

\section{DISCUSSION}

In this study, I compared patient's satisfaction and level of comfort while receiving presbyopic correction according to age with that while receiving correction according to their amplitude of accommodation, where $1 / 3^{\text {rd }}$ of the patient's accommodation was kept in reserve. I observed that patient's satisfaction after getting presbyopic correction according to age was $0 \%$ in 36-40 years age group in all the three refractive errors; it was $20 \%$ in hypermetropes in $41-45$ year age group. However in $51-55$ year age group, $100 \%$ satisfaction was found in all the three refractive errors. When presbyopic correction was given according to amplitude of accommodation keeping $1 / 3^{\text {rd }}$ of it in reserve, $100 \%$ satisfaction was seen among all the age groups between various refractive errors except for hypermetropia in $41-45$ year age group $(90.9 \%)$ which can be considered fairly good and for myopia in 56-60 year age group where only one patient out of three complained of fatigue after the use of glasses.

My findings regarding presbyopic correction correlates well with revathi et al. ${ }^{8}$, who observed the role of amplitude of accommodation in giving presbyobic correction and concluded that though age related presbyopic correction can be given in normal practice; more care has to be taken regarding the working distance range and amplitude of accommodation when coming across a young hypermetrope who tolerates individualized correction better than the conventional one.

My above findings regarding role of amplitude of accommodation in giving presbyopic correction also correlates well with Rambo and sangal ${ }^{9}$, who in 1960 , studied amplitude of accommodation in the presbyopic age group and interpreted that after thirties every refraction patient should have accommodation measured and presbyopic correction given accordingly; however after the age of 45 years this is not so important and full addition for close work or reading can usually be given.

\section{CONCLUSION}

This study tried to find out the role of amplitude of accommodation in giving presbyopic correction. In conclusion, it can be said that when presbyopic correction is given according to amplitude of accommodation in patients belonging to $36-45$ years age group, it is tolerated better and patients are more satisfied in terms of symptoms like eyestrain and headache than getting the simple correction as per their age. However after the age of 45 years, presbyopic correction given according to age is equally tolerated well among all refractive error groups. Hence, presbyopic correction in the age group of 36-45 should be given after taking the amplitude of accommodation of the individual in account and keeping $1 / 3$ of the accommodation in reserve. After the age of 45 years the conventional age old "near correction with age" can be given and is usually tolerated well.

\section{REFERENCES}

1. McBrien N, Millodot M, Neville A. Amplitude of Accommodation and Refractive Error. Invest Opth Vis Sci 1986; 27:1187-90.

2. Chattopadhay DN, Seal GN. Amplitude of accommodation in different age groups and age of onset of presbyopia in Bengali population. Indian J.Opthalmo 1984; 32:85-7.

3. Glasser A, Kaufman PL. The mechanism of accommodation in primates. Ophthalmology. 1999;106:863-72. [PubMed]

4. Schachar RA. Cause and treatment of presbyopia with a method for increasing the amplitude of accommodation. Ann Ophthalmol. 1992;24:445-7.452. [PubMed]

5. Toricelli A, Junior JB, Santiago $M$, Bechara S. Surgical Management of Presbyopia. Clin Ophthalmol. 2012;6:1459-66. [PMC free article] [PubMed].

6. Abrams D. Accommodation and Presbyopia. In: Duke - Elder's Practice of Refraction. $10^{\text {th }}$ Ed. New Delhi: Churchill Livingstone; 1995. p. 92-3.

7. Revathi M, Bhuwaneshwari N, Mohan R, Viswanathan S, Sivaprakasam, Jacob S. Role of Accommodation in giving Presbyopic correction; Proceedings of the $62^{\text {nd }}$ All India Ophthalmology Conference; 2000;29-31; Chennai.

8. Revathi, Bhuvaneshwori N, Mohan R, Sivaprakasham and Jacob s. Role of accommodation in giving presbyopic correction; preceedings of the AIOC.2002.

9. Rambo VC, Sangal SP. Study of the accommodation of the people of India. Am J Opthalmol 1960; 49:993-1004. 